\title{
HIPERINFORMAÇÃO NA ERA DIGITAL: VALIDAÇÃO DAS INFORMAÇÕES SOBRE SAÚDE
}

\author{
Mariangela Rebelo Maia \\ Doutora em Ciência da Informação IBICT/UFRJ \\ mariangela.saude@gmail.com \\ Jorge Calmon de Almeida Biolchini \\ Pesquisador do IBICT \\ jorge.biolchini@gmail.com
}

\begin{abstract}
Resumo
A ampliação dos modos de acesso à informação, particularmente através da internet, facilita que as pessoas busquem informações sobre saúde e doença. Isto inclui sintomas, diagnósticos, exames, tratamentos, medicamentos e outros itens. O objetivo nesta pesquisa é evidenciar que a hiperinformação atinge diretamente o processo de validação das informações, a disseminação de fake news e o cotidiano das pessoas. Em tempos de "informações espetacularizadas", os discursos são construídos sem compromisso com a veracidade daquilo que é informado. Não revelando as intenções pragmáticas de domínio, poder, indução e manipulação, entre outras formas de retórica. Conclui-se que a hiperinformação sobre saúde aponta para a fragilidade da veracidade informacional. Entende-se que é necessário criar condições para que a busca e o uso de informações em saúde inclua filtro e seleção de fontes comprometidas com a veracidade e a ética.
\end{abstract}

Palavras-chave: Validação da informação. Hiperinformação. Fake News.

\section{HYPERINFORMATION IN THE DIGITAL AGE: VALIDATION OF HEALTH INFORMATION}

\begin{abstract}
Increasing modes of access to information, particularly over the internet, make it easier for people to seek health and disease information. This includes symptoms, diagnoses, tests, treatments, medications and other items. The aim of this research is to show that hyper information directly affects the process of information validation, the dissemination of fake news and people's daily lives. In times of "spectacularized information", speeches are constructed without compromising with the truth of what is informed. Not revealing the pragmatic intentions of mastery, power, induction and manipulation, among other forms of rhetoric. It is concluded that hyperinformation about health points to the fragility of informational veracity. It is understood that it is necessary to create conditions for the search and use of health information to include filtering and selection of sources committed to truthfulness and ethics.
\end{abstract}

Keywords: Information validation. Hyperinformation. Fake News.

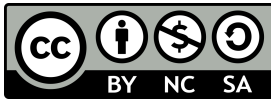




\section{INTRODUÇÃO}

Nos meados do século XX, surge a "Terceira Revolução Industrial” denominada também de "Era Digital" ou "Era da Informação". Esse tipo de revolução é proveniente de incorporações tecnológicas e produz mudanças profundas nos âmbitos social, econômico e político; afetando o cotidiano da sociedade de forma rápida, trazendo velocidade e agilidade para as nossas vidas. Atualmente, atribui-se à personalização como uma característica da “Quarta Revolução Industrial”.

Segundo a Pesquisa Brasileira de Mídia 2015 (PBM 2015) quase metade dos brasileiros usa a internet regularmente. A cada ano cresce o número de horas conectadas, diariamente, pelos brasileiros, evidenciando que o hábito de usar a de Internet está cada vez mais intenso. O percentual de pessoas que a utilizam todos os dias cresceu de 26\% na PBM 2014 para 37\% na PBM 2015 (BRASIL, 2014).

Na Pesquisa Nacional por Amostra de Domicílios Contínua (Pnad) de 2005 o Instituto Brasileiro de Geografia e Estatística (IBGE) divulgou que apenas 16\% tinham acesso à internet. Até 2013, menos da metade dos domicílios brasileiros tinham acesso à internet e somente em 2014 o país ultrapassou a marca de 50\% dos lares com conexão à rede. Segundo o levantamento, em 2016 a internet estava presente em 63,6\% dos lares e em 94,8\% deles havia celulares sendo usados para se conectar a rede.

A facilidade de acesso à internet permite que qualquer pessoa obtenha e propague informações. Porém, nem sempre há veracidade nestas informações. As notícias falsas, mais conhecidas pelo termo em inglês, fake news, circulam rapidamente, principalmente online pelas mídias sociais. As intenções na circulação de informações falsas podem ser diversas, mas o mais comum é que seja para obter ganhos financeiros ou políticos.

Essa disseminação e compartilhamento de notícias falsas cada vez mais presentes e inseridas no nosso cotidiano tornam-se mais grave quando o assunto envolve saúde, pois podem custar caro ou até mesmo, causar complicações que podem levar a sérios danos à saúde individual ou coletiva.

Isso, por conta da facilidade de acesso à internet por meio das redes sociais, sites e blogs, com uso dos smartphones que continua sendo o principal aparelho de acesso a internet, sendo utilizados por $94,6 \%$ dos internautas com a facilidade nas palmas das mãos, abriu as janelas do mundo físico e o virtual nas relações humanas. Segundo o IBGE, o Brasil fechou em 2016 com 116 milhões de pessoas conectadas a internet, o equivalente a 64,7\% mais da metade da população, só no Brasil, de acordo com dados do Facebook, a mídia social já conta com mais 
de 100 milhões de usuários ativos mensais, e a principal via de acesso são os dispositivos móveis o que facilita a troca de mensagens e compartilhamentos de forma rápida e sem restrição (IBGE, 2017).

Porém, a facilidade de acesso à internet e a hiperinformação podem gerar a banalização do conhecimento, apesar de aproximar as pessoas do conteúdo informacional. E uma grande questão a ser discutida é referente à veracidade das informações obtidas na internet, principalmente quando o objeto é a saúde.

A hiperatividade informacional moderna proporciona uma série de reflexões acerca da comunicação de conteúdos, exposição de ideias e opiniões, assim como as tomadas de decisões baseadas nessa interatividade.

Lemos (2002) considera a cibercultura como uma nova relação entre as tecnologias e a sociabilidade, configurando a cultura contemporânea, por "cibercultura compreendem-se as relações entre as tecnologias informacionais de comunicação e informação e a cultura, emergentes a partir da convergência informática/telecomunicações na década de 1970". Considerando a re-mixagem (recombinação de conteúdos) como o princípio que rege a cibercultura.

Nesta perspectiva, sendo a cibercultura uma manifestação da vitalidade social e contemporânea, o conceito de commons sofre uma evolução assumindo um espaço de esfera pública interconectada. Silveira (2007) destaca a visão de Benckler que analisa o commons a partir de dois parâmetros: primeiro, quanto ao grau de abertura (aberto a todos, ou fechados, a determinado grupo ou coletividade); segundo, quanto à existência ou não de regulação.

\begin{abstract}
A prática dos commons no contexto informacional tem adquirido mais relevância que as práticas privadas. A construção da rede das redes, a Internet, a criação do padrão http e da web, o movimento do software livre, a wikipedia, a música techno, a blogosfera, o youtube, o slashdot, o rau-tu, os sites overmundo e domínio público, o Creative Commons, o seti@home da Nasa, o BitTorrent, o barcamp e as ações P2P em geral, têm marcado a formação da comunicação e da cultura digitais. Com a influência decisiva das redes de comunicação e das tecnologias de informação nos demais segmentos da vida social, os commons entraram na pauta do temário cultural, econômico e político. (SILVEIRA, 2007, p.2)
\end{abstract}

Com o crescente uso das Tecnologias da Informação e Comunicação (TICs), a partir da década de 80 , os tecnófilos consideram somente aspectos positivos nesse "avanço" e os tecnófobos apontam enfaticamente para fatores destrutivos e submissos das TICs. Não precisamos de extremos para viver em sociedade, mas de equilíbrio, bom senso e consenso.

A cibercultura nos impregna diariamente e, na sua velocidade alucinante, traz uma liquidez de palavras e de imagens. A velocidade e a quantidade de informações contidas na rede trazem uma democratização de acesso ao conhecimento e uma globalização de informações: 
Estamos cercados de hipertextos por todos os lados. Segundo pesquisa do IBOPE referente ao mês de junho de 2009, cerca de 44,5 milhões de brasileiros conectam-se à Internet de casa ou do trabalho. Levando em conta os brasileiros de 16 anos ou mais com acesso a telefone fixo ou móvel, o IBOPE fez uma projeção de 62,3 milhões de pessoas com acesso à grande rede em todo o Brasil. $\mathrm{O}$ instituto de pesquisa considera como locais de uso as residências, trabalho, escolas, lan-houses, bibliotecas e telecentros. Uma das consequências diretas do aumento do acesso de brasileiros à Internet é o grande crescimento no tempo gasto com a navegação. Os internautas brasileiros chegaram a navegar 44h59min em um único mês (junho de 2009). Isso coloca o Brasil em primeiro lugar no ranking de tempo de conexão, ficando à frente dos americanos (40h30min), ingleses (36h20min), franceses (34h59 min), japoneses (33h03min) e alemães (29h41min). (XAVIER, 2009, p.15).

Para Helman (2009, p. 272) essa globalização nunca é "unidirecional ou impossível de ser detida, havendo muitas formas diferentes de resistir à sua influência hegemônica sobre a vida do dia a dia". As forças locais, como as resistências culturais de determinada localidade geram o que o autor denomina como "glocalização" (glocalization). Por exemplo, a medicina ayurvédica da Índia, importada para a Alemanha, que sutilmente tem sido modificada para adequar-se às expectativas culturais locais alemães de cuidados médicos.

Ainda assim, percebe-se inegável influência da globalização na reconstrução de identidades pessoais, sociais e profissionais. "Mais do que definir globalização, é necessário observar os seus efeitos nas práticas escolares e curriculares e estudar de que modo influencia o pensamento curricular" (PACHECO; PEREIRA, 2006).

A conectividade nos leva a respostas imediatas, ao "just in time", ao "groupware"2 e tantas outras facilidades momentâneas de comunicação (MORAN, 1995). As dúvidas sobre saúde podem ser buscadas na internet, nos programas de rádio ou televisão, mas sempre veiculam conhecimento ou saciam a curiosidade fugaz.

\section{INFORMAÇÃO E SAÚDE}

A palavra "informação" origina-se do latim informātı̆o, ōnis e significa 'ação de formar, de fazer, fabricação' (HOUAISS, 2008). A informação é capaz de formar o pensamento humano, trazendo conhecimento sobre algo, atribuindo significado a realidade. Portanto, a informação influencia na percepção do sujeito perante o mundo da vida, exercendo um poder

\footnotetext{
${ }^{1}$ Just In Time é um sistema de administração da produção que determina que tudo deve ser produzido, transportado ou comprado na hora exata. Pode ser aplicado em qualquer organização, para reduzir estoques e os custos decorrentes. Wikipédia Disponível em: https://pt.wikipedia.org/wiki/Just_in_time Data do acesso: 03/10/17 ${ }^{2}$ Software colaborativo (ou groupware) é um software que apoia o trabalho em grupo, coletivamente. Skip Ellis o definiu como um "sistema baseado em computador que auxilia grupos de pessoas envolvidas em tarefas comuns (ou objetivos) e que provê interface para um ambiente compartilhado". Disponível em: https://pt.wikipedia.org/wiki/Software_colaborativo Data do acesso: 03/10/17
} 
social, a informação garante a disseminação do conhecimento. Fazendo um recorte direcionado para a saúde, uma informação que gera conhecimento, pode mudar hábitos e influenciar diretamente na saúde das pessoas.

A Organização Mundial de Saúde (OMS) apresenta o conceito de saúde como "completo bem-estar físico, mental e social, e não só a ausência de doenças". Essa definição exige uma complexidade difícil de ser alcançada, mas que diariamente é buscada por todos. Sendo assim, pode-se dizer que a informação interfere na qualidade de vida da sociedade.

Em 1978, o jornal americano "The New York Times" criou uma seção sobre ciência, publicando notícias sobre os avanços médicos. E assim, o sucesso dessa abordagem sobre cuidados com a saúde foi uma prática adotada mundialmente (TABAKMAN, 2013). A informação sobre saúde garante, desta forma, seu espaço em jornais, revistas e programas de tv e, posteriormente, nas mídias sociais.

O conhecimento obtido através de informações sobre saúde na internet pode produzir efeitos positivos ou negativos, a relação emissor-receptor assume centralidade no processamento de uma informação. Muito mais que uma informação consciente, a conscientização da informação pode fazer toda diferença na saúde de um indivíduo.

Constantemente, são publicados reportagens e estudos apontando para o perigo do uso excessivo de tecnologia (celulares, jogos eletrônicos e computadores), acarretando doenças físicas e mentais, ou seja, afetando a saúde das pessoas. Inclusive, o individualismo do acesso à internet que afeta diretamente o convívio social das às pessoas, principalmente entre os jovens.

No campo da saúde, a Educação em Saúde tem forte sinergia com a comunicação (VELLOSO, 2014), pois são processos associados no desenvolvimento do saber social. Teixeira (2004) ressalta que "comunicação em saúde diz respeito ao estudo e utilização de estratégias de comunicação para informar e para influenciar as decisões dos indivíduos e das comunidades no sentido de promoverem a sua saúde".

Silva (2016) destaca que a Teoria Matemática da Comunicação (TMC) ${ }^{3}$ surge das “diversas reflexões científicas na contemporaneidade e de possibilidades objetivas de

\footnotetext{
3 A teoria matemática da comunicação estuda a quantificação, armazenamento e comunicação da informação. Ela foi originalmente proposta por Claude E. Shannon em 1948 para achar os limites fundamentais no processamento de sinais e operações de comunicação como as de compressão de dados, em um artigo divisor de águas intitulado "A Mathematical Theory of Communication". Agora essa teoria tem várias aplicações nas mais diversas áreas, incluindo inferência estatística, processamento de linguagem natural, criptografia, neurociência computacional, evolução, computação quântica, dentre outras.

A medida chave em teoria da informação é a entropia. A entropia quantifica a quantidade de incerteza envolvida no valor de uma variável aleatória ou na saída de um processo aleatório. Por exemplo, a saída de um cara ou coroa de uma moeda honesta (com duas saídas igualmente prováveis) fornece menos informação (menor entropia) do que especificar a saída da rolagem de um dado de seis faces (com seis saídas igualmente prováveis). Algumas
} 
reconhecer os aspectos materiais da informação traduzindo perspectivas para transmissão de sinais entre sujeitos (emissor e receptor)":

O discurso sobre a teoria da informação surge em um momento em que a informação conceitualmente deixa de ser vista apenas do ponto de vista de "dar forma a algo" que foi destacado desde a Antiguidade até a Idade Moderna, mas passa a ter uma carga representativa no que a transmissão de sinais e interação entre dois ou mais sujeitos. A ideia de se pensar a materialidade da informação está nas possibilidades de mensurar os suportes de informação como documentos, artefatos e até mesmo a capacidade de reprodução de mensagens em aparelhamentos analógicos e mais recentemente digitais (SILVA, 2016, p. 205).

Segundo García-Marco (2011, p. 13) as fundamentações da TMC:

Em 1949 Shannon e Weaver escrevem a Teoria Matemática da Comunicação e definem três níveis de análise do fenómeno comunicativo e da informação: a transmissão do sinal (nível 1), o significado ou semântica (nível 2) e os efeitos da mensagem, isto é, sua pragmática no sentido peirciano (nível 3). Deixam muito claro que sua teoria se centra no primeiro nível, e que os níveis superiores estão dentro do domínio de estudos das ciências sociais. De fato, os níveis de Shannon y Weaver são uma elaboração do modelo semiótico de Peirce - signo, objeto e interpretante -, que origina três níveis de análise: gramática, semiótica e pragmática.

Mas, como lidar com esse excesso de informação que o mundo digital trouxe para a sociedade moderna ainda é um vasto campo de discussão e descobertas. Em 1967, o francês Guy Debord (1931-1994) publicou o livro “A sociedade do espetáculo”, obra que se tornaria filme em 1973, que faz uma análise da sociedade moderna como uma "sociedade de espetáculo". Para o autor, o capitalismo produz uma mercantilização de tudo, gerando um consumo exagerado e fetichismo, pois as imagens tornam-se as mediadoras das relações humanas. Há, então, na sociedade uma acumulação de espetáculos, de representações; diluindo o ser humano e suas relações sociais (FIGUEIREDO, BRITO \& BOTAZZO, 2003).

Nos dias atuais, o mundo digital enalteceu a "informação espetacularizada", onde os discursos são construídos e reproduzidos sem o compromisso com a veracidade daquilo que é informado. Com isso, os discursos escondem intenções pragmáticas de domínio, poder, indução, manipulação, entre tantas outras formas de retórica.

A "overdose informativa" está criando uma geração de cibercondríacos ou midiapondríacos (MIRANDA, 2014, p. 9) “que, muitas vezes, substituem o consultório médico pelo compulsivo acesso a informações pelos meios de comunicação". Fazendo assim uma

outras medidas importantes em teoria da informação são informação mútua, informação condicional e capacidade de um canal. (Fonte: Wikipedia. Disponível em: https://pt.wikipedia.org/wiki/Teoria_da_informa\%C3\%A7\%C3\%A3o. Data do acesso: 10 jan 2018). 
alusão aos hipocondríacos ${ }^{4}$, como comumente referia-se a pessoas viciadas em doenças e medicamentos.

Para este mundo tão "fast" existe sempre um grupo contrário, o "slow". Na área médica, o manifesto da Slow Medicine $e^{5}$ possui como palavras de ordem uma medicina sóbria, respeitosa e justa. Essa filosofia "resgata a qualidade do tempo como elemento essencial da abordagem médica". Acredita-se que quando se tem um relacionamento empático com o paciente, há o fortalecimento da relação com o paciente, individualizando condutas e com escuta atenta às reais necessidades pessoais, fazendo assim, uso parcimonioso da tecnologia.

A Organização Mundial de Saúde (OMS) considera as práticas médicas e de saúde pública, auxiliadas por aparatos portáteis, como celulares, aparelhos de monitoramento dos pacientes, assistentes pessoais digitais (PDAs), e outros aparelhos sem fio. O conceito de mHealth (mobile health) ressalta a importância dessa ferramenta como suporte remoto a pacientes ou auto-promoção de cuidados em saúde (WHO, 2011).

\footnotetext{
4 A hipocondria, do grego hypo- (abaixo) e chondros (cartilagem do diafragma), também conhecida por nosomifalia, é um estado psíquico em que a pessoa tem a crença infundada de que padece de uma doença grave. Costuma vir associada a um medo irracional da morte, a uma obsessão com sintomas ou defeitos físicos irrelevantes, preocupação e auto-observação constante do corpo e até às vezes, à descrença nos diagnósticos médicos. Muitas vezes encarada como algo engraçado, a patologia é séria e prejudica a vida de pacientes e parentes. Um grande contingente de pessoas saudáveis do ponto de vista clínico e laboratorial recorre diariamente a hospitais, consultórios e prontos-socorros, sempre reclamando de doenças graves. Inconformados com médicos e exames que indicam a inexistência de qualquer problema de saúde, muitas dessas pessoas saem dali direto para a avaliação de outro profissional, na expectativa de encontrar o diagnóstico sobre o mal que supostamente os acomete. A procura será em vão e aí pode estar o indício de uma doença real, embora essa ainda não seja imaginada pelo paciente. Trata-se da hipocondria ou a 'mania de doença', como é mais conhecido o mal que se caracteriza pela supervalorização de sintomas corriqueiros e perfeitamente normais.

A hipocondria pode vir associada ao transtorno obsessivo-compulsivo e à ansiedade. (Fonte: Wikipédia. Disponível em: https://pt.wikipedia.org/wiki/Hipocondria, Data do acesso: 18 de jul de 2018).

${ }^{5}$ A primeira menção da medicina lenta (Slow Medicine) impressa ocorreu na primeira década do século XXI, cerca de quinze anos após o início do movimento slow food na Itália. Em 2002, um artigo foi publicado em uma revista médica italiana que usava as palavras "medicina lenta" para significar uma abordagem à medicina que permitiria aos profissionais tempo suficiente para avaliar o paciente e seu contexto social mais amplo, reduzir ansiedade, avaliar novos métodos e tecnologias, prevenir a liberação prematura do hospital e também fornecer suporte emocional adequado. Mais tarde, em publicações em inglês, vários médicos começaram, de forma independente, a usar o termo remédio lento. Uma sociedade de medicina lenta foi formada na Itália no ano de 2011, e a primeira conferência nacional italiana sobre medicina lenta ocorreu em Turim, Itália, em novembro de 2011. Desde então, sociedades de medicina lenta foram formadas em outros países. Diferentes médicos enfatizam diferentes aspectos da medicina quando usam o termo "remédio lento". Para alguns, a medicina lenta significa tomar tempo e não se apressar ao avaliar um paciente. Para outros, a medicina lenta é uma avaliação cuidadosa das evidências médicas e o desejo de não "superdiagnosticar" ou "sobrestimar". A sociedade original da Medicina Lenta na Itália aponta três palavras-chave: "medido", "respeitoso" e "equitativo", que se concentra nos aspectos sociais e políticos da medicina. Um dos primeiros praticantes da medicina lenta vê o paciente na metáfora de uma planta que precisa ser nutrida e que os impedimentos sejam removidos para permitir que a cura ocorra. (Fonte: Wikipédia. Disponível em: https://en.wikipedia.org/wiki/Slow_medicine, Data do acesso em: 15 de jan de 2019).
} 


\section{FAKE NEWS EM SAÚDE}

A popularização do uso da internet facilitou o acesso à informação e proporcionou um salto na produção de conteúdos publicados na Web. Portanto, facilitou a circulação e propagação de qualquer coisa, "disseminando informações falsas ("fake news"), não checadas, boatos, calúnias, difamações, entre outros, as mídias sociais, principalmente no Facebook, Twitter e WhatsApp, têm um vasto alcance e penetração no usuário comum da Internet" (SILVA FILHO; SILVA; LUCE, 2017).

Fallis (2015) trabalha com o conceito de desinformação, pois considera que a desinformação é informação, é uma informação enganosa e não é uma informação acidentalmente enganosa. Para Volkoff (2004) desinformação é um tipo de informação falsa, de manipulação voluntária.

Para Henriques (2018, p.10) "a saúde é um bom meio de cultura para boatos e rápida circulação de notícias [...] o alastramento é ainda mais rápido quando o assunto é doença grave e ameaçadora". O autor identifica "como a combinação mais perigosa acontece quando informações e orientações que contrariam o conhecimento científico são difundidas numa situação em que existe algum fato real, como uma epidemia ou uma campanha de saúde pública", como por exemplo, no caso da febre amarela, na gripe $\mathrm{H} 1 \mathrm{~N} 1$, na microcefalia e sobre o autismo, conforme a figura 1 abaixo:

Figura 1 - Fake News na saúde

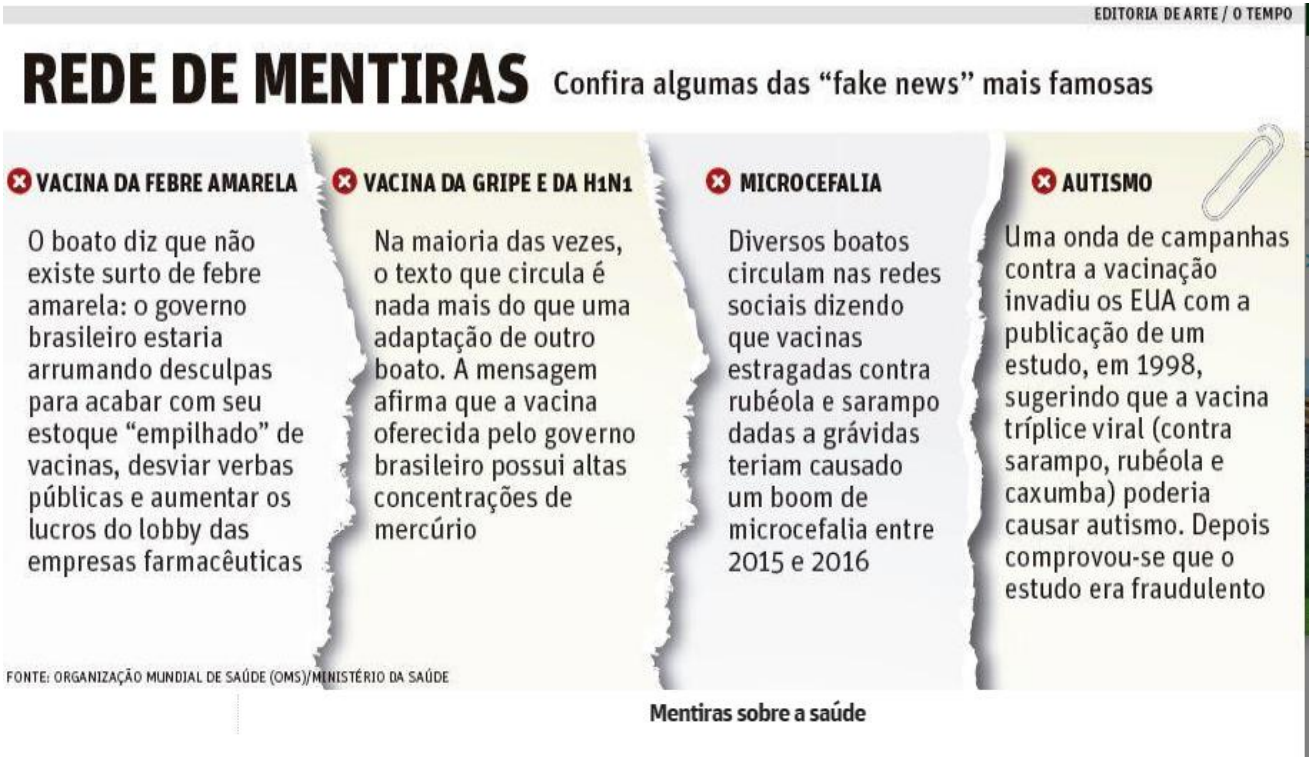

Fonte:https://www.otempo.com.br/interessa/sa\%C3\%BAde-e-ci\%C3\%AAncia/fake-newstamb\%C3\%A9m-podem-ter-impacto-negativo-na-sa\%C3\%BAde-1.1586171 
Desde 2014, uma falsa mensagem circula nas redes sociais atribuindo o aumento de casos de câncer de tireoide em mulheres por causa da realização de mamografias e de radiografias odontológicas. A circulação de fake News é cíclica, ela circula nas redes sociais, pode desaparecer por um período e voltar tempos depois.

As pessoas recebem as mensagens e sem se preocupar na checagem de sua veracidade, propagam a informação da mensagem para outras pessoas. Pode-se considerar que um desinformado é então levado muitas vezes a tornar-se um desinformador, mesmo que involuntariamente, mas movido pela propagação da informação de uma forma irracional. (VOLKOFF, 2004).

Para combater as fake news sobre saúde, o Ministério da Saúde lançou no final de agosto de 2018 um canal de comunicação com a população pelo WhatsApp, o canal "Saúde Sem Fake News". Através de deste canal, qualquer pessoa pode confirmar se uma informação recebida pelo aplicativo ou em redes sociais é verdadeira ou não. As notícias analisadas pela equipe também estarão disponíveis no Portal Saúde no endereço saude.gov.br/fakenews e nos perfis do Ministério da Saúde nas redes sociais. Em 11 meses, o ministério recebeu 10.034 mensagens (uma por hora, em média) e cerca de $90 \%$ delas foram respondidas. As notícias são checadas e recebem os seguintes selos (Figura 2):

Figura 2 - Selos nas informações checadas pelo Ministério da Saúde
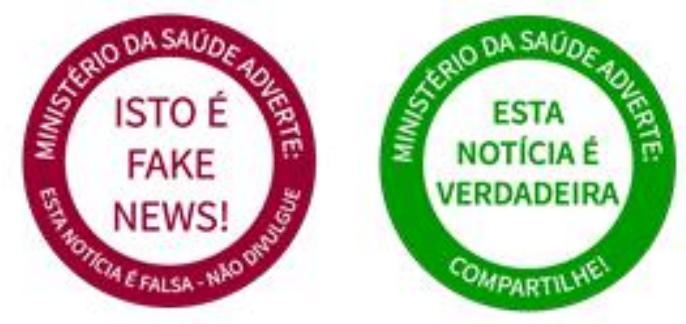

Fonte: http://www.saude.gov.br/fakenews

Nesse processo entre o emissor e o receptor das mensagens, a linguagem assume um papel primordial no uso racional e ético da informação. Um sujeito só é capaz de criar uma competência crítica da informação se dominar o uso da linguagem.

\section{PROCESSO DE VALIDAÇÃO DAS INFORMAÇÕES}

Para Lyotard (2002) o saber deve ser compreendido de duas formas distintas: o prescritivo (narrativo) e o denotativo (científico). O saber narrativo não atribui valor à sua 
própria legitimação, enquanto o saber científico precisa buscar o seu critério de legitimidade através dos seus argumentos e provas.

Há impregnação de uma racionalidade inadequada à compreensão das demandas sociais. Somente uma reconstrução comunicativa pode estabelecer trocas linguísticas desprovidas do cientificismo hegemônico.

O conceito de racionalidade de Habermas está baseado no diálogo, vinculado a uma perspectiva de entendimento com todos os sujeitos capazes de linguagem e ação. Essa forma de racionalidade refere-se à utilização comunicativa de um saber proposicional, que visa ao consenso dos diversos participantes através da força do melhor argumento, sem qualquer tipo de coerção ou repressão. Pode-se afirmar, portanto, que Habermas defende que o conceito de racionalidade comunicativa tem que ser adequadamente desenvolvido por meio de uma teoria da argumentação, partindo-se daquilo que Habermas considera como argumentação:

\begin{abstract}
Chamo argumentação ao tipo de fala em que os participantes tematizam as pretensões de validez que se tornam duvidosas e tratam de aceitá-las ou recusá-las por meio de argumentos. Uma argumentação contém razões que estão conectadas de forma sistemática com as pretensões de validez da manifestação ou emissão problematizadas. A força de uma argumentação se mede num contexto dado pela pertinência das razões (HABERMAS, 1987, p.37).
\end{abstract}

A base do entendimento mútuo eficaz para a coordenação de ação é a aceitação da pretensão de veracidade levantada para declaração de intenção ou solicitação, pretensão autenticada pela racionalidade reconhecível de uma decisão (HABERMAS, 2004, p. 119).

O convencimento da validade de afirmações problemáticas requer argumentos. Convincente é tudo aquilo que se pode aceitar como racional. Ora, a aceitabilidade racional depende do processo de argumentação, que deve permanecer aberto a qualquer tipo de objeções relevantes e a todas as melhorias impostas pelas circunstâncias. Tal prática de argumentação inclusiva e perpetuada depende de uma ideia de 'desconfinamento' de formas atuais de entendimento sobre espaços sociais, tempos históricos e competências profissionais (HABERMAS, 2007, p. 56).

O princípio do discurso refere-se a um procedimento: o resgate discursivo de pretensões de validez normativa. Nessa medida o discurso pode ser caracterizado como formal: ele não indica orientações de conteúdo, mas o processo do discurso prático. Esse não é um processo para a produção de normas justificadas, mas para o exame da validade de normas propostas ou hipotéticas. Não tem sentido querer empreender um discurso sem o horizonte do mundo da vida de um determinado grupo social e sem conflitos de ação numa determinada situação, na qual os participantes consideram como sua tarefa a regulação consensual de uma matéria social controversa (HABERMAS, 2003, p. 126). 
No agir orientado para o entendimento são especificadas as condições para um acordo a ser alcançado na comunicação. Habermas (2003, p. 164) observa que a ideia fundamental do agir orientado para o entendimento mútuo é a motivação racional de um pelo outro para uma ação de adesão. Isso acontece em virtude do efeito ilocucionário de comprometimento que a oferta de um ato de fala suscita, enquanto que no agir estratégico um atua sobre o outro para ensejar a continuação desejada de uma interação.

Habermas (1990, p. 88) destranscendentaliza o reino do inteligível a partir do momento em que desenvolve a força idealizadora da antecipação nos pressupostos pragmáticos inevitáveis dos atos de fala, portanto, no coração da própria prática do entendimento idealizações que se manifestam também e de modo mais visível na argumentação. O resgate de pretensões de validade criticáveis impõe idealizações, as quais, caídas do céu transcendental para o chão do mundo da vida, desenvolvem seus efeitos no meio da linguagem natural. Nela se manifesta também a força de resistência de uma razão comunicativa que opera contra as deturpações cognitivo-instrumentais das formas de vida modernizadas seletivamente.

A ética do discurso proposta por Habermas é cognitivista, ou seja, considera possível conhecer a verdade no campo da ética. Estabelecendo que certas proposições ligadas à moral sejam verdadeiras ou falsas. O cognitivismo implica na crença de que a razão pode ser um guia adequado do que é moralmente correto ou incorreto. Em Comentários à ética do discurso, Habermas afirma:

Tendo como ponto de referência uma comunidade comunicativa alargada de forma ideal, a teoria moral abandona também todos os conceitos pré-sociais de pessoa. A individuação é apenas o reverso da socialização. Só por meio de relações de reconhecimento recíproco é que uma pessoa pode constituir e reproduzir sua identidade. Até o âmago mais interior da pessoa está internamente ligado à periferia mais externa de uma rede extremamente ramificada de relações comunicativas. A pessoa só se torna idêntica a si própria em proporção à sua exposição comunicativa. As interações sociais que formam o Eu também o ameaçam-através das dependências em que ele se implica e das contingências a que ele se expõe. A moral actua como fonte de equilíbrio para esta susceptibilidade inerente ao próprio processo de socialização. (HABERMAS, 1991, p. 96)

O uso crítico e ético da informação requer uma competência, que exige um conjunto de conhecimentos, habilidades e atitudes sobre algo. Cavalcante et al (2012) consideram que "representa uma ou várias propostas auxiliares para a compreensão do processo de formação de cada indivíduo em termos de aprendizagem ao longo da vida e desempenho competente de suas funções profissionais, bem como humanas e cidadãs".

E o acesso, avaliação e uso da informação de forma consciente e responsável deveria ser uma regra universal. Porém, em tempos modernos, a participação dos diversos atores sociais 
na produção e uso da informação através da internet está cada vez mais sujeita a intervenções do Estado ou mesmo órgãos fiscalizadores.

Por exemplo, de olho nas falsas promessas, principalmente nas que despertam tipos físicos fora da realidade, na França, desde o dia $1^{\circ}$ de outubro de 2015, há uma lei que obriga avisar os leitores sobre o uso de programas (photoshop) em imagens de propaganda, aplicados em qualquer tipo de publicação. Assim, qualquer foto usada em um contexto comercial ou publicitário deverá ter uma tarja com a mensagem "Photographie retouchée" (foto retocada) se os corpos dos modelos tiverem sofrido qualquer tipo de alteração feita por programas de imagens digitais. Outros países já adotaram essa medida, em Israel desde 2013 é obrigatório que as alterações digitais feitas em fotos de moda sejam sinalizadas. E na Austrália, essa prática também existe, de forma voluntária, desde 2010. A principal ideia nesta proibição e tornar a mídia mais responsável pelos efeitos que ela produz nos consumidores.

A manipulação de imagens também é utilizada na saúde, principalmente em procedimentos estéticos. Além das figuras, as informações falsas e fragmentadas relacionadas à saúde tomam, cada vez mais, proporções desastrosas. Por isso, considera-se importante discutir o conceito de fake news ${ }^{6}$ em saúde, tão comuns nos dias atuais, que prestam um desserviço à saúde coletiva e um malefício à saúde das pessoas.

\section{CONSIDERAÇÕES FINAIS}

Helman (2009, p.79) considera que as "sociedades urbanizadas modernas, ocidentais ou não, são mais propensas a exibir pluralismo nos cuidados de saúde". Sendo assim, o desenvolvimento da Internet e da World Wide Web (www) solidificou a base dessa nova estrutura relacional dentro da sociedade, em rede. Web (aplicação de compartilhamento de informações de grande alcance global executado na internet) e internet (rede mundial de computadores) "não são palavras sinônimas, mas possuem estreitas relações entre si”, oferecem aos indivíduos "ferramentas de comunicação que levam ao questionamento de muitos

\footnotetext{
${ }^{6}$ Notícias falsas (sendo também muito comum o uso do termo em inglês fake news) são um tipo de imprensa marrom que consiste na distribuição deliberada e desinformação ou boatos via jornal impresso, televisão, rádio, ou ainda online, como nas mídias sociais. Este tipo de notícia é escrito e publicado com a intenção de enganar, a fim de se obter ganhos financeiros ou políticos, muitas vezes com manchetes sensacionalistas, exageradas ou evidentemente falsas para chamar a atenção. $\mathrm{O}$ conteúdo intencionalmente enganoso e falso é diferente da sátira ou paródia. Estas notícias, muitas vezes, empregam manchetes atraentes ou inteiramente fabricadas para aumentar o número de leitores, compartilhamento e taxas de clique na Internet. Neste último caso, é semelhante as manchetes "clickbait", e se baseia em receitas de publicidade geradas a partir desta atividade, independentemente da veracidade das histórias publicadas. As notícias falsas também prejudicam a cobertura profissional da imprensa e torna mais difícil para os jornalistas cobrir notícias significativas. (Fonte: Wikipédia. Disponível em: https://pt.wikipedia.org/wiki/Not\%C3\%ADcia_falsa. Data de acesso: 26 de jul de 2018).
} 
paradigmas" (GONÇALVES, 2015, p. 185). Porém, isso se traduziu, na grande maioria, em relações mais rarefeitas e vulneráveis diante de tanta informação disponível na rede digital.

A utilização da internet amplia e fragmenta, simultaneamente os nexos de comunicação, impactando no modo como o diálogo é construído entre as pessoas numa sociedade democrática. Porém, a tendência natural do ser humano de julgar fatos com base na sua própria percepção é explorada pelos meios de comunicação para fins midiáticos, econômicos ou políticos. Esse fenômeno da pós-verdade, justifica que a opinião pública reage mais a apelos emocionais do que a fatos objetivos, preferindo acreditar em determinadas informações sem checar a veracidade. A informação recorre a crenças e emoções das massas, resultando em opiniões públicas manipuladas, há uma negligência com a verdade.

Com isso, ratifica-se a ideia de Caco Xavier (2006) de contrapor "comunicação em saúde" com a "saúde na mídia". Na comunicação em saúde há "muita reflexão, mas pouca repercussão e abrangência". Na mídia surge um novo bios, o bios midiático, "uma nova forma de consciência social baseada na não-linearidade". Para o autor, "ao tentarmos nos aproximar do conceito de saúde apropriado pela mídia, os problemas são ainda maiores" (XAVIER, C. 2006, p. 45).

O conhecimento obtido através de informações sobre saúde na internet pode produzir efeitos positivos ou negativos, a relação emissor-receptor assume centralidade no processamento de uma informação. Muito mais que uma informação consciente, a conscientização da informação pode fazer toda diferença na saúde de um indivíduo. 


\section{REFERENCIAS}

BRASIL. Presidência da República. Secretaria de Comunicação Social. Pesquisa brasileira de mídia 2015: hábitos de consumo de mídia pela população brasileira. - Brasília: Secom, 2014.

CAVALCANTE, Lígia Eugênia; COSTA, Rosane Maria; NASCIMENTO, Raimundo Cézar Campos; SANTOS, Raquel Jenyffer Souza. Competência em Informação na Área da Saúde. InCID: Revista de Ciência da Informação e Documentação, Ribeirão Preto, v. 3, n. 1, p. 87-104,jan./jun. 2012.

FALLIS, D. What Is Disinformation? Library Trends, v. 63, n. 3, 2015.

FIGUEIREDO, Gustavo de Oliveira; BRITO, Dyla Tavares de Sá; BOTAZZO, Carlos. Ideologia, fetiche e utopia na saúde: uma análise a partir da saúde bucal. Ciênc. saúde coletiva [online], v.8, n. 3, p.753-763, 2003.

GARCÍA-MARCO, Francisco-Javier. La pirámide de lá información revisitada: enriqueciendo el modelo desde la ciencia cognitiva. El Profesional de la Información, v. 20, n. 1, p. 11-24, 2011.

GONÇALVES, Márcio. Wikipédia na produção discursiva do conhecimento. In: MOLLICA, Maria Cecília; BATISTA, Hadinei Ribeiro; GUIMARÃES, Ludmila dos Santos (Orgs). Cybercorpora e inovação com práticas de ensinagem. $1^{\text {a }}$ ed., Curitiba: CRV, 2015.

HABERMAS, Jürgen. A inclusão do outro: estudos de teoria política. São Paulo: Loyola, 2004.

HABERMAS, Jürgen. Comentários à ética do discurso. Lisboa: Instituto Piaget, 1991

HABERMAS, Jürgen. Consciência moral e agir comunicativo. $2^{\text {a }}$ ed. Rio de Janeiro: Edições Tempo Brasileiro, 2003.

HABERMAS, Jürgen. Entre naturalismo e religião: estudos filosóficos. Rio de Janeiro: Tempo Brasileiro, 2007.

HABERMAS, Jürgen. Pensamento pós-metafísico: estudos filosóficos. Rio de Janeiro: Tempo Brasileiro, 1990.

HABERMAS, Jürgen. Teoría de la acción comunicativa I: Racionalidad de la acción y racionalización social. Tradução de Manuel Jiménez Redondo. Madrid: Taurus, 1987.

HELMAN, Cecil G. Cultura, saúde e doença. Tradução: Ane Rose Bolner. 5 ed. Porto Alegre: Artmed, 2009. 432p.

HENRIQUES, Cláudio Maierovitch Pessanha. A dupla epidemia: febre amarela e desinformação. Reciis - Rev Eletron Comun Inf Inov Saúde, jan.-mar, v. 12, n. 1, p. 9-13, 2018.

HOUAISS, A. Dicionário Houaiss da Língua Portuguesa. Rio de Janeiro: Objetiva, 2008. 
IBGE - Instituto Brasileiro de Geografia e Estatística. Pesquisa Nacional por Amostra de Domicílios - PNAD Contínua. 2017. Disponível em: <https://www.ibge.gov.br/estatisticasnovoportal/sociais/trabalho/17270-pnad-continua.html?edicao=23205\&t=sobre $>$. Data do acesso: 01 fev. 18.

LEMOS, André. Cibercultura. Tecnologia e Vida Social na Cultura Contemporânea. Porto Alegre: Sulina, 2002.

LYOTARD, Jean-François. A Condição Pós-moderna. Trad. Ricardo Corrêa Barbosa. Rio de Janeiro: José Olympio, 2002.

MIRANDA, Amanda Souza de. Do todo à parte: curso e percurso do jornalismo especializado em saúde. Tuiuti: Ciência e Cultura [online], v. 1, p. 1-12, 2014.

MORAN, José Manuel. Novas tecnologias e o reencantamento do mundo. Revista Tecnologia Educacional. Rio de Janeiro: v. 23, n. 2, p. 126, set./ out., 1995.

PACHECO, José Augusto; PEREIRA, Nancy. Globalização e identidades educativas. Rupturas e incertezas. Revista Lusófona de Educação, n. 8, p. 13-28, 2006.

SILVA FILHO, Rubens da Costa; SILVA, Leila Morás; LUCE, Bruno. Impacto da pósverdade em fontes de informação para a saúde. Revista Brasileira de Biblioteconomia e Documentação, v. 13, p. 271-287, 2017.

SILVA, Jonathas Luiz Carvalho. A teoria matemática da comunicação na ciência da informação: propondo uma nova relação entre sujeitos da informação. Pesq. Bras. em Ciência da Inf. e Bib., João Pessoa, v. 11, n. 1, p. 203-217, 2016.

SILVEIRA, Sérgio Amadeu da. O conceito de commons na cibercultura. Trabalho apresentado no XXX Congresso Brasileiro de Ciências da Comunicação, 2007. Disponível em: http://www.intercom.org.br/papers/nacionais/2007/resumos/R1202-1.pdf. Acesso em: 2 fev. 2018.

TABAKMAN, Roxana. A saúde na mídia: medicina para jornalistas, jornalismo para médicos. São Paulo: Summus Editorial, 2013.

TEIXEIRA, José A. de Carvalho. Comunicação em Saúde. Relação Técnicos de Saúde Utentes. Análise Psicológica, v.22, n. 3, p. 615-620, 2004. Disponível em:

http://www.scielo.mec.pt/pdf/aps/v22n3/v22n3a21.pdf Acesso em: 15 de fev. 2019.

VELLOSO, Adriana de Freitas. Informação e Comunicação: análise das redes sociais e dos fluxos dos saberes entre profissionais da atenção Básica de Saúde. Tese (Doutorado em Ciência da Informação) - Escola de Comunicação, Universidade Federal do Rio de Janeiro, Programa de Pós-graduação em Ciência da Informação, Instituto Brasileiro de Informação em Ciência e Tecnologia, Rio de Janeiro, 2014. 234 p.

VOLKOFF, Vladimir. Pequena história da desinformação: do cavalo de Tróia à Internet. Curitiba: Ed. Vila do Príncipe, 2004.

WHO - WORLD HEALTH ORGANIZATION, Global Observatory for eHealth. mHealth, New Horizons for Health trough Mobile Technologies. Geneva (Switzerland): WHO; 2011. 
- INOVAção

XAVIER, Antonio Carlos A era do hipertexto: linguagem e tecnologia. Recife: Ed. Universitária da UFPE, 2009. 227 p. 